\title{
Proposal for training of workers and researchers as from the participatory return of research results in workers' health
}

\author{
Joseane Pessanha Ferreira $^{\mathrm{a} 1}$, Claudia Osorio da Silva ${ }^{\mathrm{b}}$ e Lúcia Rotenberg ${ }^{\mathrm{a}}$ \\ ${ }^{a}$ Laboratório de Educação em Ambiente e Saúde - LEAS/IOC. Fundação Oswaldo Cruz, FIOCRUZ. Av. Brasil, \\ 4365 - Manguinhos, Rio de Janeiro - RJ-Brasil. ${ }^{\mathrm{b}}$ Deparmento de Psicologia, Instituto de Ciências Humanas e \\ Filosofia, Universidade Federal Fluminense - UFF.
}

\begin{abstract}
This study streams from a perspective of Workers' Health as a field of intervention where worker's experience on the process of illness is essential to understand and generate changes in the work process, and to contribute to develop knowledge in this area. We intended to collaborate in the training of researchers and nursing workers as a means of contributing to amplify their knowledge related to work and health conditions. As a motto to promote dialogue between researchers and workers, we organized workshops to discuss the results of an epidemiological study on the work-health relationships in nursing. Ten workshops were conducted at two federal public hospitals, in the city of Rio de Janeiro, Brazil. The main aspects discussed during the workshops revealed (i) work nuances for which the questionnaire was not sufficiently sensitive, (ii) some associations between different aspects of the survey, dealt with in the questionnaires, and (iii) recognition that some aspects shown in the epidemiological results were experienced at work. One can appreciate that the proposal presented here contributed to the training of researchers and workers, amplifying their knowledge and contributing to the development of the activity.
\end{abstract}

Keywords: Participatory return of research results; Three-Pole Dynamic Device; training.

\footnotetext{
${ }^{1}$ Corresponding author. E-mail: joseane@ioc.fiocruz.br
} 


\section{Introduction}

The study presented here is part of the "Health and Work in Nursing" research, that uses quantitative and qualitative approaches to investigate health-work relations in nursing teams. It streams from a perspective of Workers' Health as a field of intervention where worker's experience on the process of illness is essential to understand and generate changes in the work process, and to contribute to develop knowledge in the process [1]. Consonant to this vision, authors in this area have criticized the limited contribution of Science to the field, since approaches have focused exclusively on epidemiology or solely to human and social sciences, or solely to toxicology, leading to a fragmented, unidisciplinary and dispersed knowledge. Some authors in the area call attention to the challenge to be faced in actions in Workers' Health in relation to the present practice of social control: "We believe that, unfortunately, the instruments created for the exercise of this kind of citizenship have not been effective, often limiting, or hindering the discussion of issues crucial to address the current situation in the workplace" [1] (p.806). It can be said that necessary relevance must be given to the participation of workers in actions and decisions concerning health-work relationships.

The present proposal arose from the research group's criticism to the simply informational method of returning results, which relied on brochures and books. This data provides a description of work and health conditions, besides fulfilling the ethical commitment of returning results to workers. They furnish a general panorama of health and work conditions, therefore are potentially useful to occupational health commissions and to the representative bodies of the category. However, the use of this material in itself was considered insufficient to deal with a central question in this field of study, which is, the active participation of workers in the construction of knowledge. At different moments of the fieldwork, the workers questioned the value of research in improving working conditions. Although it was not possible or desirable to answer directly to this demand, these issues stimulated a proposal of action directed to enhancing the dialogue with workers.

It is necessary, therefore, to consider the nature of the problem-solving dialogue as the means by which mankind gains significance in the line proposed by Freire [7]. As science representatives, we seeked dialog with workers as the means of validating results, since only a relationship of "empathy" between the poles in the dialog will produce a transforming communication [6]. Thus, in the relationship with the workers we followed this author's approach to the educational process, since "no matter how fundamental be the contents, the real importance is not only in them, but in the way they are apprehended by the trainees and incorporated to their practice" [8] ( p.87).

In order to meet the objective of joining workers and researchers in result discussion workshops (here referred to as "workshops") and to produce new material on health-work relationships, we used the ergological approach as a tool [10]. Such approach advocates dialogue between the knowledge of experience and knowledge of academy, based on his Three-Pole Dynamic Device.

This device describes the articulation between three poles or three dialog dimensions: (i) the concepts pole, constituted by the material originated from scientific matters, (ii) the pole related to the workers' experience and knowledge from work and (iii) the ethical commitment pole. This "third pole is the device's bind, as it deals with the ethics necessary to construct the relations of partnership in a determined philosophy of humanity, regarding the other as his fellow" [3] (p. 101-102). This three-pole device is situated in training, being necessary to reconstruct this notion: not only master the knowledge that will be shared, but recognize the other part's knowledge, who is seen as a holder of "re-creative differences in his activity" [10] (p.267) - therefore training involves "being equally available" [10] (p.267) to learn from the other.

For Schwartz [11], the three-pole device has an effect on the production of knowledge and management of work, understanding that these two environments have a reciprocal relationship.

We depart, therefore, from an ethical perspective, understood as necessary to the construction of partnerships, regarding the other as one's equal [3]. So the device is to be used as a tool that "streamlines the relationship between scientific knowledge and work experience, which is not simple, nor does it appear in similar conditions in the various realities that are being apprehended" [3] (p. 102).

It is believed that the Three-Pole Dynamic Device is a powerful tool to act not only in the production of knowledge but also in the work situation, as has been discussed by various groups in Brazil [5]. It is estimated that such a device may contribute to the 
proposed return of epidemiological results from a methodology based on dialogue between the knowledge derived from scientific disciplines and knowledge arising from the experience of workers.

This way, the research results were used as tools for training not only researchers but also workers with respect to the development of their activities. It is believed that the proposal to discuss the research results suggests a synergy between academic and workers practice knowledge so as to contribute to the collective construction of knowledge on the relationship between work organization and health, focusing on practical actions for the improvement of working conditions.

\section{Objective}

It was intended to assist with this proposal, the training of researchers and workers from the return of the results of an epidemiological survey, contributing to expanding the knowledge of researchers and workers about their work and health conditions.

\section{Methodology}

As a motto to promote dialogue between researchers and workers, we organized workshops for the discussion of the results of an epidemiological study on the relationship of health and work in nursing. The epidemiological study had been carried out in 2006; it was based on a 35-page questionnaire with questions about work, health and, about house and family (such as income, how many people inhabit, children, their ages and responsibilities regarding domestic chores). Workers were addressed at their work place, in different shifts and were invited to answer the questionnaire right there during their workday.

We carried out ten workshops to discuss the epidemiological results at two federal public hospitals, in Rio de Janeiro, Brazil, between 2007 and 2009. At both hospitals it was relevant to contact the head nurse and the occupational health commission to reinforce the presence of the research team in those hospitals and, especially, to evaluate the possibilities of carrying out the workshops and establish a partnership. This partnership was seen as important for the activity's success, based on the parties understanding the proposal as an occupational health action strategy. Other factors that contributed to the relevance of this partnership were practical issues, since they would be responsible for the liberation of workers interested in participating, and would assist in the reservation of space for the meetings and to free access to the area for dissemination and implementation of activities in different shifts.

In the first experience, at a large general hospital, four workshops were accomplished, three during night shifts and one at daytime. To carry out the workshops a prior survey on employees' interest in participating was made, including best time and place, besides the time available for the duration of activities. From these results the workshops were announced throughout all hospital sectors and invitations were posted on each employee's worksheet, offering two workshop possibilities, in order to allow participation of all of those interested. Before the meetings, the work sectors would be contacted by phone, to confirm the presence of those workers enrolled and once again invite other workers who had not signed up previously, but that could be interested and available to attend the meeting.

To facilitate the discussion in the workshops, the research team elected some descriptive results (sex, age, employment and professional category) and others seen as more challenging (for example,. hypertension related to weekly working hours and shift work and use of time by men and women) which were shown in pie or bar charts posted on the workshop walls.

At the time of the workshops' disclosure at the hospital, workers questioning the contribution of research to improvements in working conditions was fairly frequent, showing a demand that the research team act out as those who would indicate, from their knowledge, the solutions to the problems faced by workers. Although we considered workers as indispensable actors for any actions and decisions related to the work process and health conditions, the research team did assume the workers demand of "How this survey could be useful for nursing staff?" as relevant, trying to answer it during workshops. This strategy, to a certain extent, hindered dialogue between academy and experience knowledge from the ethical point of view of understanding the other party as an equal, since it could have reinforced the idea that the research team, could unilaterally, present and make viable solutions to some of the problems related to the worker's health.

However, we understand that these experiences contributed to the researchers' training, expanding 
their knowledge of the research activity itself, from some adjustments in the method used for the result discussion workshops to be carried out at the second hospital (medium size maternal and infant hospital). Besides, there was a larger investment in widespreading the activities, and steps leading up to the workshops were also improved, including voting for the more interesting themes for workers to discuss during the workshops, aiming from the beginning to a greater worker participation. The invitations for participating included head nurses and the occupational health commission, both understood as partners in the construction of new possibilities in the hospital's health-work relationship.

At this second hospital, six workshops were accomplished, three during day time and three nightshifts. In this new phase, we sou In this new phase, we sought to present survey results in a less static way, available to the handling of workers. Besides results, magazine/internet pictures that could be related to different themes dealt with in the questionnaire were displayed, especially those chosen by workers. Results were presented in folded pieces of paper, where at first only the graphic's theme was visible, to allow results seen here as not finalised or as a unilateral interpretation made by the researchers, be contested. Each participant was asked to chose two or more results and/or pictures that had called their attention, and during the discussion were asked to tell, from the viewpoint of their work experience, the reason for their choice and what they imagined (if they imagined) the study had found as a result. Another innovation regarding the workshop method referred to the suggestion of producing a poster that depicted what had been discussed by that group. Such material, according to the proposal, was mainly to help disclose what had been discussed during workshops to other hospital instances and workers, allowing it to trigger other movements and collective actions to improve occupational health, as a possible consequence of these meetings.

\section{Results and Discussion}

The main aspects of the health-work relationship discussed during the workshops revealed (i) the disagreement of workers on some results presented by the research team; (ii) associations between different aspects of the work process, treated in the questionnaire; and (iii) the recognition of some of the results as a realistic portrait of what is experienced at work.

With regard to the disagreements we can mention an example of result non-validation presented in a workshop in which the group discussed its weekly schedule. To workers, the result obtained in the epidemiological questionnaire (portrayed by that data) was not as they had experienced it, but referred to the quantity of working hours allowed to nursing professionals, as illustrated in one worker's utterance: "Another data that also can't be very real is this one: the number of working hours per week (...) I think we work much more than 60 hours... I... It wasn't said then for a reason - civil servants are not allowed to work more than 60 hours per weekso they omitted this information, because reality is quite different. This is not the graphic..."

An association seen as important in a workshop by a group of workers was about physical work, which ought to be considered according to the sector and professional category. One of the workers doubted the graphic in which a result displayed high physical labour by nurses, "nurses do not experience heavy physical labour, this is done by the nurse aides, because nurses at the clinic deal more with the bureaucratic aspects, the part of physical effort relies on nurse aides. , Now, I don't know about the other sectors". In another passage of her speech, from the differentiation she made about clinic and ward work, it was also possible to understand what this nurse considered as physical effort: "because in the wards, nurses do have to take care of patients, bathe them... now, at the clinics I don't see that. The task of ... all the task of physical contact with patients, it is the nurse aide who does it. The part of the... nurses... they even do that interview prior to consultation. Now, physical effort, which is the case if you are carrying a patient after sedation to a resting room, or moving a patient from a stretcher to an... examination bed, that is really the nurse aide's task. I don't see nurses doing that. But, it's different on the floor [referring to the wards], on the floors I don't know how it is, they might participate. But in the clinics I don't see nurses doing it. I think it's not quite the same."

However some data was validated by the group of workers, as corresponding to what they experienced at work. These acknowledgements, in a way, helped putting the work process as a theme for discussion, contributing to an improvement of knowledge about this process, by workers participating in the discussion workshops. The following speech, about 
support by fellow workers, portraits the validation of data and recognition of this aspect as fundamental for work to be accomplished the best way: "Another point is that at work one can count on support in difficult situations. And then I opened this research of yours, and $77 \%$ of people agree and 23\% disagree, right? (...) I think a good relationship with people who are willing to help you favours you to be able to do a better job or worse, finally. (...) And I imagine that, err, that it can be difficult or almost impossible to work at an IC or in a ward among people you cannot count on, I think it would be impossible. Since nursing is a continuous task and that, it suggests a group work, working in a good ambience is, really, very helpful. That's it."

In sum, the main aspects discussed during the workshops were: work nuances for which the questionnaire is not sufficiently sensitive, the magnification of researcher's knowledge with regard to the nursing work and its possible relationship with health, producing new results from workers experiences and the encounters of knowledge, and the development of the activities of nursing workers from the recognition, discussion (and in some cases the questioning) of their working process developed from the results of the research in epidemiology.

By using the research results as possible analysis devices, we tried to produce new results from workers' and researchers' views and knowledge, both (workers and researchers) being invited to participate in the process of analysing and understanding these results. Thus, we did not depart from the understanding that results speak for themselves, or only from the researcher's analysis as the ones who "know" the subject. It is then a proposal of research-intervention as advised by Institutional Analysis (Loureau, 1993) where subjects and objects of knowledge construct themselves at the same time and place where the moment of practice is also the moment of producing theory (Passos and Barros, 2000). In this sense, restitution is seen as a process that tries to allow researcher and researched abandon their crystallized roles, besides contributing to maximization of the apparent schism between theory and practice, favouring a collective analysis discussion of knowledge produced (Ayres \& cols, 2005), resulting in something new.

The partnership established by researchers, occupational health commission and chief nurses at both hospitals allowed the proposal be constructed collectively, formulating from their collaborations, a method to be used in result discussion workshops and of worker mobilization strategies (specially at the second hospital), and distribution of Result Tablets (at the first hospital). These examples show the continuous character of restitution (Loureau, 1993), that occurred not only at the end of the research, but during its entire length.

A very important aspect relating workshop results was the actual research team's movement in order to change the workshop format at the second hospital, trying to present research results to workers in a closer and friendlier way. This change was due to self-criticism towards the workshop method used at the first hospital, by understanding from that occasion, that the ecstatic way the graphs had been shown could have influenced their lesser acceptance by workers, hindering dialogue between academic and experience knowledge.

Thus, one can evaluate the proposal presented here could contribute to the training of researchers and workers, expanding their knowledge and helping improve their activity. These experiences led to advances to workers, mainly in what refers to (re)thinking their work process, and to researchers, regarding deepening of data obtained in the questionnaire. They also contributed to build a relationship of trust between workers and researchers (which may not have been established during the epidemiological step), favouring a more powerful action of the workers about their working and health conditions.

\section{References}

[1] C. Minayo-Gomez and F.A.C Lacaz, Saúde do Trabalhador: novas-velhas questões, in: Ciência \& Saúde Coletiva 2005; 10 n.4: pp. 797-807.

[2] E. Passos and R.B. Barros, A construção do plano da clínica e o conceito de transdisciplinaridade, Psicologia: Teoria e Pesquisa 2000, 16 n.1: pp.71-9.

[3] J. Brito, Saúde do trabalhador: reflexões a partir da abordagem ergológica, in: Figueiredo M, Athayde M, Brito J, Alvarez D, organizadores, Labirintos do Trabalho: interrogações e olhares sobre o trabalho vivo, Rio de Janeiro: DP\&A, 2004, pp. 91-114.

[4] L.S.M. Ayres, D. O. Rodrigues, F.M. Maciel, F.A.M. Souza, F.M.L. Ribeiro, D. Flores, et al, Redesenhando o lugar da pesquisa - Experimentando a prática da restituição, Mnemosine 2005, 1 n.1: pp.394-406.

[5] M. Figueiredo, M. Athayde, J. Brito and D. Alvarez, orgs, Labirintos do Trabalho: interrogações e olhares sobre o trabalho vivo, Rio de Janeiro: DP\&A, 2004. 
[6] P. Freire, Educação e Mudança / Paulo Freire, tradução de Moacir Gadotti e Lillian Lopes Martin, Rio de Janeiro: Paz e Terra, 1979, Coleção Educação e Comunicação vol.1

[7] P. Freire, Pedagogia do oprimido, 12a edição. Rio de Janeiro: Paz e Terra, 1983.

[8] P. Freire, Política e educação / Paulo Freire - 8 . Edição revisada e ampliada, Indaiatuba, SP - Vila das Letras, 2007.
[9] R. Lourau, René Lourau na UERJ: Análise Institucional e Práticas de Pesquisa, Rio de Janeiro, UERJ, 1993.

[10]Y. Schwartz and L. Durrive (org), Trabalho e Ergologia: conversas sobre a atividade humana, Niterói: Eduff, 2007.

[11]Y. Schwartz, A comunidade científica ampliada e o regime de produção de saberes, Trabalho \& Educação, 7: pp.38-46, 2000. 